\title{
Possible Role of HLA-G, LILRB1 and KIR2DL4 Gene Polymorphisms in Spontaneous Miscarriage
}

\author{
Izabela Nowak ${ }^{1}$ Andrzej Malinowski ${ }^{2} \cdot$ Ewa Barcz $^{3} \cdot$ Jacek R. Wilczyński $^{4}$ • \\ Marta Wagner $^{1}$ - Edyta Majorczyk ${ }^{1,5}$ - Hanna Motak-Pochrzęst ${ }^{5,6}$. \\ Małgorzata Banasik $^{7} \cdot$ Piotr Kuśnierczyk ${ }^{1}$
}

Received: 20 October 2015/ Accepted: 28 January 2016/Published online: 14 March 2016

(C) The Author(s) 2016. This article is published with open access at Springerlink.com

\begin{abstract}
The KIR2DL4 receptor and its ligand HLA-G are considered important for fetal-maternal immune tolerance and successful pregnancy. The absence of a particular variant of KIR2DL4 might be a bad prognostic factor for pregnancy outcome. However, it could be compensated by the presence of the respective LILRB1 allele. Therefore, we investigated the KIR2DLA, LILRBI and HLA-G polymorphisms in 277 couples with spontaneous abortion and 219 control couples by HRM, PCR-SSP and RFLP
\end{abstract}

Electronic supplementary material The online version of this article (doi:10.1007/s00005-016-0389-7) contains supplementary material, which is available to authorized users.

Izabela Nowak

izan@iitd.pan.wroc.pl

Piotr Kuśnierczyk

pkusnier@iitd.pan.wroc.pl

1 Laboratory of Immunogenetics and Tissue Immunology, Department of Clinical Immunology, Ludwik Hirszfeld Institute of Immunology and Experimental Therapy, Polish Academy of Sciences, Rudolfa Weigla 12, 53-114 Wroclaw, Poland

2 Department of Surgical, Endoscopic and Oncologic Gynecology, Polish Mothers' Memorial Hospital-Research Institute, Lodz, Poland

3 First Chair and Clinic of Obstetrics and Gynecology, Medical University of Warsaw, Warsaw, Poland

4 Department of Gynecology and Gynecologic Oncology, Polish Mothers' Memorial Hospital-Research Institute, Lodz, Poland

5 Faculty of Physical Education and Physiotherapy, Opole University of Technology, Opole, Poland

6 Obstetric Gynecological Department, Disctrict Hospital Strzelce Opolskie, Strzelce Opolskie, Poland

7 APC, Medical Analyses, Lodz, Poland methods. We found a protective effect of women's heterozygosity in -716 HLA-G $(p=0.0206)$ and LILRBI ( $p=0.0131)$ against spontaneous abortion. Surprisingly, we observed more 9A/10A genotypes of KIR2DL4 gene carriers in the group of male partners from the miscarriage group in comparison to the men from the control group $(p=0.0288)$. Furthermore, there was no association of women's KIR2DLA polymorphism with susceptibility to spontaneous abortion. Multivariate analysis indicated that women's -716 HLA-G and LILRB1 and men's KIR2DL4 $9 \mathrm{~A} / 10 \mathrm{~A}$ are important in terms of the protection or susceptibility to miscarriage, respectively $(p=0.00968)$. In conclusion, a woman's heterozygosity in $H L A-G$ and LILRB 1 might be an advantage for a success of reproduction, but the partner's heterozygosity in 9A/10A KIR2DL4 alleles might not.

Keywords HLA-G · LILRB1 - Linkage disequilibrium · KIR2DL4 $\cdot$ Spontaneous abortion

\section{Introduction}

Spontaneous abortion has been described as a condition where a multifactorial background plays a role in its etiology (Christiansen 2013; Diejomaoh 2015; Larsen et al. 2013; Sugiura-Ogasawara et al. 2014). The pathomechanism of spontaneous miscarriage is still not completely understood. Many scientists are searching for an explanation of this disease in immunological pathways, because the fetus is perceived by the mother as a semiallograft, which in normal pregnancy is not rejected (Medawar 1953). Many researchers are also looking for genetic biomarkers as a diagnostic tool. Among receptors which may have an influence on decidual-trophoblast cell 
interactions in pregnancy are KIR2DL4 (killer cell immunoglobulin-like receptor, two domains, long cytoplasmic tail, 4), LILRB1 (leukocyte immunoglobulin-like receptor, subfamily B, member 1) and their ligand, HLA-G (human leukocyte antigen G) ( $\mathrm{Li}$ et al. 2009).

KIR2DL4 is unique among KIRs because of its structure, cellular localization and expression. This receptor possesses a single ITIM (immunoreceptor tyrosine-based inhibitory motif) in its cytoplasmic tail and a positively charged arginine in the transmembrane region. Therefore, it can potentially inhibit or activate cells functions. KIR2DL4 is expressed by natural killer (NK) CD56 $6^{\text {bright }}$ cells and appears on the majority of decidual-placental NK cells but not on peripheral NK CD56 $6^{\text {bright }}$ cells (Makrigiannakis et al. 2011; Rajagopalan and Long 2012).

The 9A allele of the KIR2DL4 gene with the deletion of one adenine in exon 7 produces either a protein with a truncated cytoplasmic tail or one lacking the transmembrane region. This causes a lack of KIR2DL4 expression at the cell surface. In contrast, 10A alleles encode receptors that can be expressed at the cell surface (Goodridge et al. 2007, 2009). Hence, KIR2DL4 polymorphism may have an influence on the interaction of decidual NK cells with HLA-G expressed on trophoblastic cells. Moreover, we could speculate that absence of KIR2DL4 could be compensated by the presence of a particular allele of LILRB1, also named ILT-2 (immunoglobulin-like transcript-2) (Li et al. 2009). LILRB1 as well as KIRs was found in a gene cluster at chromosomal region 19q13.4. Multiple transcript variants encoding different isoforms have been found for this gene. The encoded protein contains four extracellular immunoglobulin domains, a transmembrane domain, and four cytoplasmic ITIMs (Martin et al. 2002). The receptor, which is expressed on immune cells (Apps et al. 2007) and placental stromal cells, primarily on fibroblasts and macrophages (McIntire et al. 2008), may bind to HLA-G and transduce a negative signal that inhibits stimulation of an immune response.

Even though HLA-G is classified as a non-classical class I HLA because of limited tissue distribution and lower polymorphism, 51 alleles of this molecule were identified (The IMGT database; October 2015). The most polymorphic sites of $H L A-G$ were found in the promoter (positions $-725,-716$ ), in exon 8 , and in $3^{\prime}$ UTR (14 base pair insertion/deletion) of the gene, resulting in variation of HLA-G expression. The $H L A-G$ gene, due to alternative splicing of its transcript, encodes seven proteins: four are bound with membrane (HLA-G1 to HLA-G4), while three (HLA-G5 to HLA-G7) appear as soluble proteins (Dahl and Hviid 2012; Donadi et al. 2011; Menier et al. 2010). In pregnancy, expression of HLA-G is determined by the kind of trophoblast and stage of pregnancy progression. HLA-G membrane-bound molecules (of maternal and paternal origin) are presented by all extravillous trophoblast subpopulations. Moreover, soluble isoforms (HLA-G5-7) were detected in maternal-fetal circulation, amniotic fluid, and all trophoblasts, including the syncytiotrophoblast, which is deprived of membrane-bound class I antigens (Dahl and Hviid 2012; McIntire et al. 2008).

In our case-control study we tested different genetic variants of KIR2DL4 (9A/10A alleles and three intronic positions near this poly-adenine fragment), LILRBI (rs41308748 $\mathrm{G}>\mathrm{A})$ and $H L A-G(-725 \mathrm{C}>\mathrm{G}>\mathrm{T},-716$ $\mathrm{T}>\mathrm{G}$ in the promoter region and a 14 base pair insertion/ deletion in $3^{\prime} \mathrm{UTR}$ ) in patients with spontaneous abortion and control women as well as in male partners of these two groups. To our knowledge, this is the first report concerning cumulative genotypes of KIR2DL4, LILRBI and $H L A-G$ in couples and the possible association with miscarriage.

\section{Materials and Methods}

\section{Study Design}

All patients (and their partners) participating in the study were recruited from the Department of Surgical, Endoscopic and Oncologic Gynecology and Department of Gynecology and Gynecologic Oncology, Polish Mothers' Memorial Hospital-Research Institute, Poland. Two hundred and seventy-seven couples, who had experienced spontaneous abortion (2-8 miscarriages) but were free from chromosomal aberrations, uterine anomalies, hormonal disturbances, and infections with Toxoplasma, Chlamydia, Listeria, and Brucella, were originally qualified for our study. Among them, 79 couples had two miscarriages (sporadic spontaneous abortion, SSA, with the mean age $32.08 \pm 3.85$ years; age range $25-41$ ). The remaining group of 198 couples belonged to the recurrent spontaneous abortion group (RSA; with the mean age $32.78 \pm 4.00$ years; age range $24-46$ ). These were selected on the basis of a history of three or more first trimester spontaneous abortion incidents with the same partner. Moreover, among the RSA group we selected 115 women $(58.1 \%)$ without autoantibodies. The remaining group of 83 RSA women $(41.9 \%)$ possessed a different set of autoantibodies, such as anticardiolipin, antinuclear, antithyroid, anti- $\beta$-glycoprotein, and factor LA. In the sporadic abortion group we could distinguish those possessing autoantibodies ( 35 women, $44.3 \%$ ) and without autoantibodies (40 women, $50.6 \%)$. We had no data regarding autoantibodies concerning four women $(5.1 \%)$ from the SSA group. As we realized that our patient group was heterogeneous (in terms of presence of autoantibodies, factor V Leiden, antiphospholipid syndrome and mutations in MTHFR $677 C>T$ and 
$1298 A>C$ positions), we decided to include all collected couples and use a multivariate analysis.

The control group was recruited from the 1st Department of Obstetrics and Gynecology, Medical University of Warsaw and from the Disctrict Hospital Strzelce Opolskie. This group consisted of 219 healthy couples with at least two healthy-born children and no history of miscarriage or endocrinological or immunological disorders: women with the mean age $32.29 \pm 5.81$ years, age range $22-68$, and their partners with the mean age $33.97 \pm 6.18$ years, age range 25-70. Men from the spontaneous abortion group had a similar age to the men from the control group: mean age $34.2 \pm 3.15$ years, age range $27-41$. Thus, both control and spontaneous abortion groups were age-matched. All tested individuals were of Polish origin. Experimental protocols were approved by the Local Ethics Committees (the agreement of Medical University of Wroclaw and Polish Mothers' Memorial Hospital-Research Institute in Łódź) and informed consent was obtained from all individual participants included in the study.

\section{DNA Preparation and Genotyping}

Genomic DNA was isolated from venous blood using the Invisorb Spin Blood Midi Kit (Invitek, Berlin, Germany) following the manufacturer's instructions.

KIR2DL4 9A/10A alleles (rs11410751) and three other single nucleotide polymorphisms (SNPs) spanning the vicinity of the poly-adenine fragment, i.e. rs660773-position $9797 \mathrm{G}>\mathrm{A}$ (intron 7), rs660437—position $9769 \mathrm{C}>\mathrm{A}$ (intron 7), rs649216-9571 C > T (762), were distinguished by the high resolution melting (HRM) method and by restriction fragment length polymorphism (RFLP), respectively. Details of the genotyping have been described recently in details elsewhere (Nowak et al. 2015).

$H L A-G$ genotyping in positions $-725 \quad \mathrm{C}>\mathrm{G}>\mathrm{T}$ (rs1233334) and $-716 \mathrm{~T}>\mathrm{G}$ (rs2249863) was conducted by temperature gradient gel electrophoresis, and the 14 base pair insertion/deletion (rs66554220) of $H L A-G$ was tested by the PCR-SSP (sequence-specific priming) method. Both methods have been described previously by Wiśniewski et al. (2010).

MTHFR $677 C>T$ and MTHFR $1298 A>C$ genotyping is described in Supplementary Material 1 and Supplementary Fig. 1-4.

LILRB1 5651G $>$ A position (rs41308748, located in the 14th intron) genotyping is described in Supplementary Material 2 and Supplementary Figs. 5, 6. rs41308748 showed minor allele frequency (MAF) in controls (both women and men) MAF $\leq 0.09$. To predict possible functional effects for this SNP we used the website: http:// fastsnp.ibms.sinica.edu.tw (Yuan et al. 2006), which proposed it as the splicing site with the risk at the 3-4 level (with maximum 4).
The LILRB1 5651 genotype distributions were deviated from Hardy-Weinberg equilibrium (HWE) (Tables 1, 2). Therefore, we sequenced 14 AA genotype samples (from all 22), seven samples for GA and five samples for GG genotype. We repeated digestion for 11 samples because of the suspicion of the partial digestion.

\section{Statistical Analysis}

Chi-square, $\chi^{2}$, test was used to test the hypothesis that two groups have the same the distribution of genotype counts. When the sample sizes were small, distributions of the test statistics were estimated numerically. Odds ratio (OR) and confidence interval for them at $1-\alpha=0.95$ were computed as the measures of effect size. When it was reasonable, we assumed log additive model of association between genotype and risk of miscarriages. Genetic differences between cases $(Y=1)$ and controls $(Y=0)$ were tested with model $h[P(Y=1 \mid \underline{x})]=\alpha+\underline{\beta}^{T} \underline{x}$, where $\underline{x}$ is matrix of genetic predictors and $h$ is logit. Number of miscarriages, $k$, among cases was investigated with model defined as $h[P(Y \leq k \mid \underline{x})]=\alpha_{k}+\underline{\beta}^{T} \underline{x}$. Results were adjusted to age, autoantibodies and $M T H F R$ polymorphisms. When necessary, coefficients $\alpha, \beta$ and their standard errors were estimating with bootstrap sampling $(B=4999)$. To summarize predictive power of the model we used a measure of proportional reduction in sum of squared errors (SSE) i.e. quasi- $R^{2}=1-S S E_{\hat{y}} / S S E_{\bar{y}}$. Multicollinearity was measured based on Pearson's correlation coefficients of $\underline{x}_{n \times k}$ matrix, $\mathbf{R}_{k \times k}$, as $\operatorname{det} \mathbf{R}_{k \times k} \in[0,1]$ and $\operatorname{det} \mathbf{R}_{k \times k}=1$ in case of $\mathbf{R}_{k \times k}=\mathbf{I}$.

Hellinger distance, $H \in[0,1]$, was used as the measure of divergence between two multinomial probability distributions $p$ and $q$ with $N$ classes as $H=\sqrt{1-\sum_{i=1}^{N} \sqrt{p_{i} q_{i}}}$ (Matusita 1955). Haplotype frequencies were estimated with maximum likelihood function (Excoffier and Slatkin 1995). Departure from HWE was measured as $f=\frac{p_{C C}-p_{C}^{2}}{p_{C}\left(1-p_{C}\right)}$, where $p_{\mathrm{C}}$ and $p_{\mathrm{CC}}$ are allele $C$ and genotype $C C$ frequencies. $f<0$ in case of deficiency of homozygotes, $f>0$ corresponds to deficiency of heterozygotes and $f=0$ when locus is in HWE.

As there were no differences in frequencies of tested gene polymorphisms between recurrent miscarriage group (i.e., those with three or more spontaneous abortions) and those with two miscarriages, we could treat both groups as genetically homogenous population. Also, we had no information whether patients with two miscarriages got pregnant later and gave birth to a healthy child. Rather, we could presume that they got miscarriage. So there is no basis to distinguish between Cases A and Cases B group, therefore we pooled these groups in analyses (Tables 1,2). Our decision to include patients with two miscarriages to analyses was supported also by the fact that many 
Table 1 Genotype frequencies in women group according to cases and controls

\begin{tabular}{|c|c|c|c|c|c|c|c|c|c|c|c|}
\hline \multirow[t]{2}{*}{ Polymorphism } & & \multicolumn{2}{|c|}{ Cases A } & \multicolumn{2}{|c|}{ Cases B } & \multicolumn{2}{|c|}{ Controls $^{\mathrm{a}}$} & \multirow[t]{2}{*}{$\mathrm{OR}^{\mathrm{b}}$} & \multicolumn{2}{|c|}{ CI $95 \%$} & \multirow[t]{2}{*}{$\overline{\text { Cases vs. controls }}$} \\
\hline & & $N$ & $\%$ & $N$ & $\%$ & $N$ & $\%$ & & & & \\
\hline \multirow[t]{6}{*}{ HLA-G 14 bp ins/del } & del/del & 27 & 34.2 & 73 & 36.9 & 74 & 33.8 & 1 & & & $\chi_{d f=4}^{2}=6.91$ \\
\hline & del/ins & 30 & 38 & 91 & 45.9 & 110 & 50.2 & 0.82 & 0.55 & 1.21 & $p=0.1407$ \\
\hline & ins/ins & 22 & 27.8 & 34 & 17.2 & 35 & 16 & 1.18 & 0.70 & 1.98 & \\
\hline & $\sum$ & 79 & 100 & 198 & 100 & 219 & 100 & & & & \\
\hline & H-W & \multicolumn{2}{|c|}{$p=0.0415$} & \multicolumn{2}{|c|}{$p=0.5551$} & \multicolumn{2}{|c|}{$p=0.6754$} & & & & \\
\hline & $f$ & \multicolumn{2}{|c|}{0.237} & \multicolumn{2}{|c|}{0.044} & \multicolumn{2}{|c|}{-0.04} & & & & \\
\hline \multirow{8}{*}{ HLA-G -725} & $\mathrm{CC}$ & 52 & 65.8 & 134 & 67.7 & 152 & 69.4 & 1 & & & $\chi_{d f=6}^{2}=4.69$ \\
\hline & $\mathrm{CG}$ & 19 & 24.0 & 50 & 25.3 & 57 & 26 & 0.99 & 0.66 & 1.49 & $p=0.8051$ \\
\hline & $\mathrm{CT}$ & 4 & 5.1 & 7 & 3.5 & 5 & 2.3 & 1.71 & 0.61 & 4.83 & \\
\hline & GG & 4 & 5.1 & 6 & 3 & 5 & 2.3 & 1.56 & 0.54 & 4.48 & \\
\hline & GT & 0 & 0 & 1 & 0.5 & 0 & 0 & 2.45 & - & - & \\
\hline & $\sum$ & 79 & 100 & 198 & 100 & 219 & 100 & & & & \\
\hline & H-W & \multicolumn{2}{|c|}{$p=0.2833$} & \multicolumn{2}{|c|}{$p=0.8097$} & \multicolumn{2}{|c|}{$p=0.9989$} & & & & \\
\hline & $f$ & \multicolumn{2}{|c|}{0.049} & \multicolumn{2}{|c|}{0.014} & $0.01 \mathrm{c}$ & & & & & \\
\hline HLA-G -716 & $\mathrm{TT}$ & 23 & 29.1 & 51 & 25.8 & 58 & 26.5 & 1 & & & $\chi_{d f=4}^{2}=7.19$ \\
\hline & GT & 32 & 40.5 & 102 & 51.5 & 122 & 55.7 & 0.86 & 0.57 & 1.31 & $p=0.1262$ \\
\hline & GG & 24 & 30.4 & 45 & 22.7 & 39 & 17.8 & 1.38 & 0.82 & 2.32 & \\
\hline & $\sum$ & 79 & 100 & 198 & 100 & 219 & 100 & & & & \\
\hline & H-W & $p=$ & 141 & $p=$ & 759 & $p=$ & 784 & & & & \\
\hline & $f$ & 0.18 & & -0.0 & & -0.12 & & & & & \\
\hline KIR2DL4 9620 & $9 \mathrm{~A} / 9 \mathrm{~A}$ & 22 & 27.8 & 52 & 26.3 & 66 & 30.1 & 1 & & & $\chi_{d f=4}^{2}=0.86$ \\
\hline & $9 \mathrm{~A} / 10 \mathrm{~A}$ & 38 & 48.1 & 100 & 50.5 & 103 & 47 & 1.19 & 0.79 & 1.81 & $p=0.9302$ \\
\hline & $10 \mathrm{~A} / 10 \mathrm{~A}$ & 19 & 24.1 & 46 & 23.2 & 50 & 22.8 & 1.16 & 0.71 & 1.90 & \\
\hline & $\sum$ & 79 & 100 & 198 & 100 & 219 & 100 & & & & \\
\hline & H-W & $p=$ & 218 & $p=$ & 896 & $p=$ & 174 & & & & \\
\hline & $f$ & 0.03 & & -0.0 & & 0.05 & & & & & \\
\hline KIR2DL4 9571 & TT & 23 & 29.1 & 55 & 27.8 & 71 & 32.4 & 1 & & & $\chi_{d f=4}^{2}=1.19$ \\
\hline & $\mathrm{CT}$ & 38 & 48.1 & 100 & 50.5 & 103 & 47 & 1.22 & 0.81 & 1.84 & $p=0.8797$ \\
\hline & $\mathrm{CC}$ & 18 & 22.8 & 43 & 21.7 & 45 & 20.5 & 1.23 & 0.75 & 2.03 & \\
\hline & $\sum$ & 79 & 100 & 198 & 100 & 219 & 100 & & & & \\
\hline & H-W & $p=$ & 216 & $p=$ & 874 & $p=$ & 952 & & & & \\
\hline & $f$ & 0.03 & & -0.0 & & 0.04 & & & & & \\
\hline KIR2DL4 9769 & $\mathrm{CC}$ & 53 & 67.1 & 135 & 68.2 & 147 & 67.1 & 1 & & & $\chi_{d f=4}^{2}=6.53$ \\
\hline & $\mathrm{CA}$ & 23 & 29.1 & 63 & 31.8 & 66 & 30.1 & 1.02 & 0.69 & 1.50 & $p=0.1589$ \\
\hline & AA & 3 & 3.8 & 0 & 0 & 6 & 2.7 & 0.42 & 0.11 & 1.57 & \\
\hline & $\sum$ & 79 & 100 & 198 & 100 & 219 & 100 & & & & \\
\hline & $\mathrm{H}-\mathrm{W}$ & $p=$ & 153 & $p=$ & 056 & $p=$ & 187 & & & & \\
\hline & $f$ & 0.02 & & -0.18 & & -0.02 & & & & & \\
\hline KIR2DL4 9797 & GG & 23 & 29.1 & 55 & 27.8 & 70 & 32 & 1 & & & $\chi_{d f=4}^{2}=0.97$ \\
\hline & GA & 38 & 48.1 & 100 & 50.5 & 103 & 47 & 1.20 & 0.80 & 1.81 & $p=0.9131$ \\
\hline & AA & 18 & 22.8 & 43 & 21.7 & 46 & 21 & 1.19 & 0.72 & 1.96 & \\
\hline & $\sum$ & 79 & 100 & 198 & 100 & 219 & 100 & & & & \\
\hline & H-W & $p=$ & 216 & $p=$ & 874 & $p=$ & 948 & & & & \\
\hline & $f$ & 0.03 & & -0.0 & & 0.04 & & & & & \\
\hline
\end{tabular}


Table 1 continued

\begin{tabular}{|c|c|c|c|c|c|c|c|c|c|c|c|}
\hline \multirow[t]{2}{*}{ Polymorphism } & & \multicolumn{2}{|c|}{ Cases A } & \multicolumn{2}{|c|}{ Cases B } & \multicolumn{2}{|c|}{ Controls $^{\mathrm{a}}$} & \multirow[t]{2}{*}{$\mathrm{OR}^{\mathrm{b}}$} & \multicolumn{2}{|c|}{ CI $95 \%$} & \multirow[t]{2}{*}{ Cases vs. controls } \\
\hline & & $N$ & $\%$ & $N$ & $\%$ & $N$ & $\%$ & & & & \\
\hline \multirow[t]{6}{*}{ LILRB1 5651} & GG & 69 & 87.3 & 172 & 86.9 & 182 & 83.1 & 1 & & & $\chi_{d f=4}^{2}=4.28$ \\
\hline & GA & 10 & 12.7 & 22 & 11.1 & 35 & 16 & 0.69 & 0.41 & 1.16 & $p=0.3688$ \\
\hline & AA & 0 & 0 & 4 & 2 & 2 & 0.9 & 1.36 & 0.29 & 6.46 & \\
\hline & $\sum$ & 79 & 100 & 198 & 100 & 219 & 100 & & & & \\
\hline & H-W & \multicolumn{2}{|c|}{$p=0.5481$} & \multicolumn{2}{|c|}{$p=0.0159$} & \multicolumn{2}{|c|}{$p=0.6806$} & & & & \\
\hline & $f$ & \multicolumn{2}{|c|}{-0.067} & \multicolumn{2}{|c|}{0.207} & \multicolumn{2}{|c|}{0.015} & & & & \\
\hline
\end{tabular}

Cases $A$ patients with two miscarriages, Cases $B$ patients with three or more miscarriages, $N$ number of cases, $P$ probability, $O R$ odds ratio, $95 \%$ $C I$ confidence interval, $H-W$ Hardy-Weinberg equilibrium, $f<0$ corresponds to deficiency of homozygotes, $f>0$ corresponds to excess of homozygotes, $f=0$ in case of $\mathrm{H}-\mathrm{W}$

${ }^{a}$ Frequencies of KIR2DL4 polymorphisms in controls were described previously by Nowak et al. (2015)

${ }^{\mathrm{b}}$ OR computed for [cases A plus cases B] vs. controls

researchers have now included two pregnancy losses to RSA, because childless couples became more prevalent in recent decades (Diejomaoh 2015; Sugiura-Ogasawara et al. 2014).

\section{Results}

The distribution of genotypes of tested polymorphic positions in the women's group with miscarriages and control women is shown in Table 1. In turn, Table 2 shows the distribution of these SNPs in men from the miscarriage group and from controls.

After analysis of Tables 1 and 2 we could not find evidence for KIR2DLA, LILRB1, or HLA-G genotype association with a risk of spontaneous abortion for both women and their partners. However, in this analysis we considered an association of particular polymorphism without including any information of genotype in the remaining SNPs.

Table 3 presents results from the analysis of all tested SNPs and their total phenotype effect with respect to sex. A GT heterozygous woman in position -716 of $H L A$ $G$ had over 1.5 times lower chance of miscarriage in comparison to a woman who was homozygous in this SNP (OR $=0.64, p=0.0206)$. A woman who was heterozygous in the LILRB1 $5651 G>A$ position, possessed 2.5 times lower probability of abortion in comparison to a homozygous GG or AA woman in this $\mathrm{SNP}(\mathrm{OR}=0.40$, $p=0.0131)$. However, the association of the two discussed SNPs (HLA-G and LILRBI) was not additive. If protective effect of heterozygosity in the $H L A-G-716$ $T>G$ and the LILRBI $5651 \quad G>A$ were additive then expected ratio for double heterozygote would be $\mathrm{OR}=0.24$. Nevertheless, observed value is $\mathrm{OR}=0.62$ with CI $95 \%(0.22 ; 1.76)$, so we conclude that true effect is not additive and protective effect of double heterozygosity is the same as the one of the two considered. This overall protective effect is estimated as $\mathrm{OR}=0.58, \mathrm{CI}$ $95 \%(0.42 ; 0.81)$. We can also infer from Table 3 that a man's genotype in a fragment of polyA of the KIR2DL4 gene was associated with miscarriage of his partner. The likelihood of abortion in a woman with a $9 \mathrm{~A} / 10 \mathrm{~A}$ partner was 1.49 times higher than in a woman with a homozygous partner $(p=0.0288)$. To summarize the results in Table 3 we can say that all these factors were important in terms of the protection (women's -716 HLA-G and LILRBI) or susceptibility (men's KIR2DL4 9A/10A) to miscarriage $(p=0.00968)$.

Otherwise, none of the remaining polymorphic positions had any association with miscarriage $\left(x_{d f=13}^{2}=3.02\right.$, $p=0.9979)$, including woman's genotype in polyA of the KIR2DL4 gene $(p=0.8397)$.

KIR2DL4 and LILRB1 genes are parts of the same chromosome and are located in the leukocyte region complex, so we analyzed haplotype frequencies in SNPs of both genes in women and men from patients and the control group (Supplementary Material 3). We found no association of particular haplotype with miscarriage, both for women $(p=0.2043)$ and men $(p=0.3804)$. Although the haplotype 10A-C-A-A-A was 18 times less frequent in cases than in controls, but its frequency was low in both groups, as it contained rare LILRB1 5651A allele.

The analysis of $H L A-G$ haplotypes (Table 4) presents no differences in all haplotypes frequencies of tested females groups and also their partners, so the Hellinger distances are minor $(H=0.075, H=0.066$, respectively).

The final step of our analysis was to include some clinical information concerning the patient group (age, number of miscarriages, week of miscarriage, 
Table 2 Genotype frequencies in men group according to cases and controls

\begin{tabular}{|c|c|c|c|c|c|c|c|c|c|c|c|}
\hline \multirow[t]{2}{*}{ Polymorphism } & & \multicolumn{2}{|c|}{ Cases A } & \multicolumn{2}{|c|}{ Cases B } & \multicolumn{2}{|c|}{ Controls $^{\mathrm{a}}$} & \multirow[t]{2}{*}{$\mathrm{OR}^{\mathrm{b}}$} & \multicolumn{2}{|c|}{ CI $95 \%$} & \multirow[t]{2}{*}{ Cases vs. controls } \\
\hline & & $\mathrm{N}$ & $\%$ & $\mathrm{~N}$ & $\%$ & $\mathrm{~N}$ & $\%$ & & & & \\
\hline \multirow[t]{6}{*}{ HLA-G 14 bp ins/del } & del/del & 29 & 36.7 & 61 & 30.8 & 75 & 34.2 & 1 & & & $\chi_{d f=4}^{2}=1.57$ \\
\hline & del/ins & 30 & 38 & 81 & 40.9 & 91 & 41.6 & 1.02 & 0.67 & 1.53 & $p=0.8136$ \\
\hline & ins/ins & 20 & 25.3 & 56 & 28.3 & 53 & 24.2 & 1.19 & 0.75 & 1.90 & \\
\hline & $\sum$ & 79 & 100 & 198 & 100 & 219 & 100 & & & & \\
\hline & H-W & \multicolumn{2}{|c|}{$p=0.0418$} & \multicolumn{2}{|c|}{$p=0.0107$} & \multicolumn{2}{|c|}{$p=0.02$} & & & & \\
\hline & $f$ & \multicolumn{2}{|c|}{0.23} & \multicolumn{2}{|l|}{0.18} & \multicolumn{2}{|l|}{0.16} & & & & \\
\hline \multirow[t]{8}{*}{ HLA-G -725} & $\mathrm{CC}$ & 43 & 54.5 & 142 & 71.7 & 145 & 66.2 & 1 & & & $\chi_{d f=6}^{2}=11.1$ \\
\hline & $\mathrm{CG}$ & 31 & 39.2 & 46 & 23.3 & 55 & 25.1 & 1.10 & 0.73 & 1.65 & $p=0.1959$ \\
\hline & $\mathrm{CT}$ & 3 & 3.8 & 6 & 3 & 12 & 5.5 & 0.60 & 0.25 & 1.42 & \\
\hline & GG & 2 & 2.5 & 3 & 1.5 & 5 & 2.3 & 0.78 & 0.24 & 2.61 & \\
\hline & GT & 0 & 0 & 1 & 0.5 & 2 & 0.9 & 0.47 & - & - & \\
\hline & $\sum$ & 79 & 100 & 198 & 100 & 219 & 100 & & & & \\
\hline & H-W & \multicolumn{2}{|c|}{$p=0.5701$} & \multicolumn{2}{|c|}{$p=0.9154$} & \multicolumn{2}{|c|}{$p=0.9989$} & & & & \\
\hline & $f$ & \multicolumn{2}{|c|}{-0.09} & \multicolumn{2}{|c|}{-0.008} & 0.00 & & & & & \\
\hline HLA-G -716 & TT & 28 & 35.4 & 42 & 21.2 & 52 & 23.7 & 1 & & & $\chi_{d f=4}^{2}=7.76$ \\
\hline & GT & 27 & 34.2 & 95 & 48 & 105 & 47.9 & 0.86 & 0.56 & 1.35 & $p=0.1008$ \\
\hline & GG & 24 & 30.4 & 61 & 30.8 & 62 & 28.3 & 1.02 & 0.63 & 1.65 & \\
\hline & $\sum$ & 79 & 100 & 198 & 100 & 219 & 100 & & & & \\
\hline & H-W & $p=$ & 064 & $p=$ & 681 & $p=$ & 385 & & & & \\
\hline & $f$ & 0.3 & & 0.03 & & 0.03 & & & & & \\
\hline KIR2DL4 9620 & 9A/9A & 22 & 27.8 & 59 & 29.8 & 74 & 33.8 & 1 & & & $\chi_{d f=4}^{2}=4.12$ \\
\hline & $9 \mathrm{~A} / 10 \mathrm{~A}$ & 42 & 53.2 & 103 & 52 & 95 & 43.4 & 1.39 & 0.93 & 2.09 & $p=0.3904$ \\
\hline & $10 \mathrm{~A} / 10 \mathrm{~A}$ & 15 & 19 & 36 & 18.2 & 50 & 22.8 & 0.93 & 0.57 & 1.54 & \\
\hline & $\sum$ & 79 & 100 & 198 & 100 & 219 & 100 & & & & \\
\hline & H-W & $p=$ & & $p=$ & 747 & $p=$ & 756 & & & & \\
\hline & $f$ & -0. & & -0.0 & & 0.12 & & & & & \\
\hline KIR2DL4 9571 & TT & 22 & 27.8 & 59 & 29.8 & 78 & 35.6 & 1 & & & $\chi^{2}=4.1$ \\
\hline & CT & 42 & 53.2 & 103 & 52 & 95 & 43.4 & 1.47 & 0.98 & 2.20 & $p=0.3921$ \\
\hline & $\mathrm{CC}$ & 15 & 19 & 36 & 18.2 & 46 & 21 & 1.07 & 0.64 & 1.76 & \\
\hline & $\sum$ & 79 & 100 & 198 & 100 & 219 & 100 & & & & \\
\hline & H-W & $p=$ & & $p=$ & 747 & $p=$ & 979 & & & & \\
\hline & $f$ & -0. & & -0.0 & & 0.11 & & & & & \\
\hline KIR2DL4 9769 & $\mathrm{CC}$ & 53 & 67.1 & 144 & 72.7 & 170 & 77.6 & 1 & & & $\chi_{d f=4}^{2}=4.07$ \\
\hline & $\mathrm{CA}$ & 23 & 29.1 & 45 & 22.7 & 42 & 19.2 & 1.39 & 0.90 & 2.15 & $p=0.4033$ \\
\hline & $\mathrm{AA}$ & 3 & 3.8 & 9 & 4.6 & 7 & 3.2 & 1.44 & 0.57 & 3.64 & \\
\hline & $\sum$ & 79 & 100 & 198 & 100 & 219 & 100 & & & & \\
\hline & H-W & $p=$ & 153 & $p=$ & 568 & $p=$ & 597 & & & & \\
\hline & $f$ & 0.02 & & 0.15 & & 0.14 & & & & & \\
\hline KIR2DL4 9797 & GG & 22 & 27.8 & 56 & 28.3 & 77 & 35.2 & 1 & & & $\chi_{d f=4}^{2}=4.6$ \\
\hline & GA & 42 & 53.2 & 107 & 54 & 97 & 44.3 & 1.51 & 1.01 & 2.27 & $p=0.3304$ \\
\hline & $\mathrm{AA}$ & 15 & 19 & 35 & 17.7 & 45 & 20.5 & 1.10 & 0.66 & 1.82 & \\
\hline & $\sum$ & 79 & 100 & 198 & 100 & 219 & 100 & & & & \\
\hline & H-W & $p=$ & & $p=$ & 495 & $p=$ & & & & & \\
\hline & $f$ & -0. & & -0.0 & & 0.09 & & & & & \\
\hline
\end{tabular}


Table 2 continued

\begin{tabular}{|c|c|c|c|c|c|c|c|c|c|c|c|}
\hline \multirow[t]{2}{*}{ Polymorphism } & & \multicolumn{2}{|c|}{ Cases A } & \multicolumn{2}{|c|}{ Cases B } & \multicolumn{2}{|c|}{ Controls $^{\mathrm{a}}$} & \multirow[t]{2}{*}{$\mathrm{OR}^{\mathrm{b}}$} & \multicolumn{2}{|c|}{ CI $95 \%$} & \multirow[t]{2}{*}{ Cases vs. controls } \\
\hline & & $\mathrm{N}$ & $\%$ & $\mathrm{~N}$ & $\%$ & $\mathrm{~N}$ & $\%$ & & & & \\
\hline \multirow[t]{6}{*}{ LILRB1 5651} & GG & 66 & 83.5 & 162 & 81.8 & 190 & 86.7 & 1 & & & $\chi_{d f=4}^{2}=2.24$ \\
\hline & GA & 10 & 12.7 & 28 & 14.1 & 24 & 11 & 1.31 & 0.76 & 2.25 & $p=0.6987$ \\
\hline & AA & 3 & 3.8 & 8 & 4.1 & 5 & 2.3 & 1.74 & 0.62 & 4.90 & \\
\hline & $\sum$ & 79 & 100 & 198 & 100 & 219 & 100 & & & & \\
\hline & $\mathrm{H}-\mathrm{W}$ & \multicolumn{2}{|c|}{$p=0.026$} & \multicolumn{2}{|c|}{$p=0.0006$} & \multicolumn{2}{|c|}{$p=0.0046$} & & & & \\
\hline & $f$ & \multicolumn{2}{|l|}{0.3} & \multicolumn{2}{|l|}{0.28} & \multicolumn{2}{|c|}{0.235} & & & & \\
\hline
\end{tabular}

Cases A patients with two miscarriages; Cases B patients with three or more miscarriages, $N$ number of cases, $P$ probability, $O R$ odds ratio, $95 \%$ $C I$ confidence interval, $H$-W Hardy-Weinberg equilibrium, $f<0$ correspond to deficiency of homozygotes, $f>0$ correspond to excess of homozygotes, $f=0$ in case of $\mathrm{H}-\mathrm{W}$

a Frequencies of KIR2DL4 polymorphisms in Controls were described previously by Nowak et al. (2015). ${ }^{\text {b }}$ Odds ratio computed for [cases A plus cases B] vs. controls

Table 3 Estimated odds ratios (OR) in model for odds of miscarriage by HLA-G (-716), LILRB1 (rs41308748) and KIR2DL4 polyA polymorphisms

\begin{tabular}{|c|c|c|c|c|}
\hline Polymorphism & OR & CI 95 & & $p$ \\
\hline HLA-G -716 women: GT & 0.64 & 0.43 & 0.93 & 0.0206 \\
\hline LILRB1 women: GA & 0.40 & 0.19 & 0.82 & 0.0131 \\
\hline KIR2DL4 men: 9A/10A & 1.49 & 1.04 & 2.13 & 0.0288 \\
\hline HLA-G -716 women: GT $\times$ LILRB1 women: GA & 0.62 & 0.22 & 1.76 & 0.0761 \\
\hline
\end{tabular}

$\operatorname{det} \mathbf{R}_{3 \times 3}=0.998 ;$ quasi $-\mathrm{R}^{2}=0.0266$

$\chi_{\mathrm{df}=4}^{2}=13.35, p=0.00968$

$\beta_{0}=0.3955$ CI $95 \%(0.074 ; 0.717)$

Woman: HLA-G (-716) not GT \& LILRB1 not GA plus partner KIR2DL4 not 9A/10A assumed as baseline

$P$ probability, $O R$ odds ratio, $C I 95 \%$ confidence interval

Table 4 Haplotype frequencies of $H L A-G$ polymorphisms in men and women group among miscarriages cases and controls, sorted by frequency in cases women

\begin{tabular}{|c|c|c|c|c|c|c|c|c|}
\hline \multicolumn{3}{|c|}{ HLA-G haplotypes } & \multicolumn{3}{|l|}{ Women } & \multicolumn{3}{|l|}{ Men } \\
\hline ins/del & -725 & -716 & Cases $(\%)$ & Controls $(\%)$ & $\mathrm{RR}$ & Cases $(\%)$ & Controls (\%) & $\mathrm{RR}$ \\
\hline ins & $\mathrm{C}$ & G & 37.85 & 39.00 & 0.97 & 46.7 & 41.78 & 1.12 \\
\hline del & $\mathrm{C}$ & $\mathrm{T}$ & 33.59 & 37.66 & 0.89 & 30.05 & 29.22 & 1.03 \\
\hline del & G & $\mathrm{T}$ & 15.63 & 14.55 & 1.07 & 13.11 & 15.30 & 0.86 \\
\hline del & $\mathrm{C}$ & G & 10.64 & 6.66 & 1.60 & 8.10 & 10.50 & 0.77 \\
\hline ins & $\mathrm{T}$ & $\mathrm{T}$ & 2.02 & 1.10 & 1.84 & 1.77 & 3.20 & 0.55 \\
\hline ins & G & $\mathrm{T}$ & 0.28 & 0.74 & 0.38 & 0.27 & 0.00 & - \\
\hline$\Sigma$ & & & 100 & 99.71 & - & 100 & 100 & - \\
\hline \multicolumn{3}{|c|}{ Cases vs. controls } & \multicolumn{3}{|c|}{$\chi_{d f=5}^{2}=7.34 ; p=0.1965$} & \multicolumn{3}{|c|}{$\chi_{d f=5}^{2}=5.68 ; p=0.3386$} \\
\hline
\end{tabular}

Ins 14 bp insertion in $3^{\prime}$ UTR of $H L A-G$, Del 14 bp deletion in $3^{\prime}$ UTR of $H L A-G, R R$ ratio Cases/Controls, $P$ probability, $H$ Hellinger distance

autoantibodies, antiphospholipid syndrome, MTHFR $677 C>T, M T H F R$ 1298A $>C$ ). None of the above-cited variables exhibited an association with the number of miscarriages $\left(\chi_{d f=11}=5.48, p=0.9055\right)$.

\section{Discussion}

In our case-control study, we tried to elucidate an association of particular genetic variants of KIR2DL4, LILRB1 and its ligand $H L A-G$ in women as well as in their partners 
with susceptibility to spontaneous abortion. To date, no association of maternal KIR2DL4 polymorphism with RSA and preeclampsia has been reported (Witt et al. 2002, 2004), and our results are concordant with Witt et al. (2004). Moreover, reports of fertile women who lacked KIR2DL4 and delivered babies have been published by Gómez-Lozano et al. (2003) and Nowak et al. (2011) implying that this gene is not essential for reproduction. However, KIR2DL4 is one of the "framework" genes, and its loss is rare because only several individuals lacking this gene have been reported to date (Gómez-Lozano et al. 2003; Niepiekło-Miniewska et al. 2014; Nowak et al. 2011). On the other hand, a lack of KIR2DL4 gene and its receptor on the surface of immune cells might be compensated by the presence of receptors belonging to the LILR family, e.g. LILRB1. Indeed, we found that the women's GA heterozygosity in LILRBI seems protective (Table 3). It is worth emphasizing that the distribution of LILRBI genotypes in the control group is in HWE, but in the group of patients is not (Table 1). This independently suggests the association of LILRBI GA with protection against disease. rs41308748, as the splicing site, could have an influence on the creation of LILRB1 variants with decreased inhibitory function of receptors resulting in activation of local immune cells to produce cytokines and growth factors necessary for successful embryo implantation and subsequent maintenance of pregnancy. Moreover, one of the ITIMs in the LILRB1 was reported to possess an immunoreceptor tyrosine-based switch motif (ITSM; SXVXXV), and the binding of adaptors signaling lymphocyte activation molecule-associated protein and Ewing's sarcoma-associated transcript to an ITSM can convert receptors from inhibitory to activating function ( $\mathrm{Li}$ et al. 2009). Such isoforms may act instead of KIR2DL4, which emerged in this study not associated with susceptibility to miscarriage or protection against disease in female patients. Moreover, the studies on the crystal structure of KIR2DL4 showed that this receptor oligomerizes to tetramers possibly because of the absence of D0 domain glycosylation (Moradi et al. 2015). This was supposed to preclude an interaction of receptor with HLA. Indeed, Moradi et al. (2015) were unable to detect an interaction between KIR2DL4 and a panel of 100 pHLA-Ia or HLA-G by single HLA-antigen bead assay and by surface plasmon resonance. Therefore, a self-association of KIR2DL4 could regulate ligand binding and subsequent signal transduction.

An interesting aspect of our analysis was the observation of the significantly higher frequency of $9 \mathrm{~A} / 10 \mathrm{~A}$ $K I R 2 D L 4$ genotype in men belonging to the miscarriage group (Table 3). Why the genotype of man's KIR $2 D L 4$ is important in susceptibility to miscarriage of his partner, but KIR2DL4 genotype of the woman is not, is hard to explain. There are no literature data regarding the role of
KIR2DL4 genotype of a man in miscarriage of his partner. Recently, the expression of some KIRs (2DL1, 2DL2/3, 3DL1 but not KIR2DL4 which was not tested in that study) in neonatal cord blood has been reported by Schonberg et al. (2011), showing that KIR repertoires of neonatal NK cells are diverse but not biased toward recognition of self HLA class I. However, neonatal NK cells were functional at the level of antibody-dependent cellular cytotoxicity and cytokine production. As early as 1992, Phillips et al. revealed that human NK cells develop early in utero, as they have been detected in fetal liver at the sixth week of gestation and in fetal spleen at gestational week 15. The evidence for the NK cells differentiation and inhibitory KIR expression was also identified by Ivarsson et al. (2013) in the majority of fetal lung NK cells but also spleen and bone marrow from 15 to 22 gestational age. These fetal NK cells were hyporesponsive to HLA-negative target cells. From tenth week of gestation on, the fetus absorbs amniotic fluid which contains cytokines, antibodies, maternal cells and sometimes pathogens. High proportion of differentiated NK cells in the fetal lungs was supposed to protect against fetal infection. In turn, the hyporesponsiveness of these cells to HLA-negative cells could potentially prevent the recognition of maternal semi-allogeneic cells by fetal NK cells. Whether scenario, in which the paternal KIR2DL4 allele inherited by the fetus could have an impact on NK cells responses in the developing fetus is likely, remains to be elucidated. However, the expression of KIR2DL4 and LILRB 1 receptors in both primary trophoblasts and trophoblastic cell lines (JAr and JEG-3) has been described by Guo et al. (2013). Moreover, these receptors were functional as trophoblast invasion was induced by binding soluble HLA-G5 to KIR2DL4 and LILRB1. In addition, KIR2DL4 can interact with heparan sulfate/heparin glycosaminoglycans (GAGs), an alternative ligand, and these interactions can affect receptor function (Brusilovsky et al. 2013, 2014). Therefore, we may hypothesize that trophoblast KIR2DL4 inherited from the father may interact with GAG-containing proteoglycans, and that this interaction may be affected by KIR2DL4 polymorphism.

All genotype distributions in control women were in HWE (Table 1). Moreover, frequencies of 9A and 10A position 9620 insertion/deletion alleles and alleles in the two intronic positions 9571 and 9797 of KIR2DL4 approximated to $50 \%$. The presence of $9 \mathrm{~A}$ and $10 \mathrm{~A}$ alleles in populations in equal frequency has been postulated to indicate balancing selection (Goris et al. 2009; Le Page et al. 2013; Witt et al. 2000). We previously reported that above-mentioned KIR2DL4 polymorphisms in healthy fertile Polish population were in strong positive linkage disequilibrium (Nowak et al. 2015). This complete LD between KIR2DL4 9620 and 9571 positions allowed us to 
confirm our results in two independent methods, namely HRM and RFLP.

Polymorphisms of $H L A-G$ in promoter positions -716 $\mathrm{T}>\mathrm{G}$ and $-725 \mathrm{G}>\mathrm{C}>\mathrm{T}$ were previously reported to be linked with methylation status of the gene which had an influence on the transcriptional activity, because of the vicinity to the interferon-stimulated response element (Donadi et al. 2011). The $-725 \mathrm{G}$ variant present in both spouses was associated with sporadic miscarriage in Hutterites (a genetically isolated sect of Anabaptists) (Ober et al. 2003). We also tested possible association of the $-725 \mathrm{G}$ allele with the number of miscarriages. However, we did not find such an association in our outbred group of sporadic or recurrent abortion, neither in women nor in their partners, separately or in couples. On the other hand, we found a protective effect from miscarriage of -716 GT heterozygosity. Possibly, the higher heterozygosity in this locus may be enforced by natural selection as it has been observed for other MHC genes (Meyer et al. 2006; Penn et al. 2002). Heterozygotes in MHC may perceive twice more antigens than homozygotic carriers so they could be resistant to broader spectrum of pathogens. Therefore, heterozygosity in HLA-G may here play a role of a marker of classical HLA heterozygosity in mothers, which might favor a maintenance of pregnancy. Moreover, mother could transmit her HLA-G allele to the fetus which, when expressed in the fetus, could be recognized by her LILRB1. This may result in secretion of cytokines from decidual leucocytes to induce immune tolerance allowing trophoblast migration and vascular remodeling during placental development.

Deviation from HWE in the $14 \mathrm{bp}$ in/del of HLA$G$ and SNP in LILRBI not only in male partners from the miscarriage group but also in control men was seen. Note that control men were selected from the whole Polish population by their partners having at least two healthy-born children and no history of abortion. Consequently, this group was not random as in the case of a group of, e.g. unrelated blood donors and therefore a bias in our study could occur. Indeed, in our earlier study (Wiśniewski et al. 2015) a larger control group, unselected for fertility, did not deviate from HWE in these both genes. However, we feel that our 219 fertile couples are better control for miscarriage and other pregnancy disorders, than those published earlier by others, e.g. primiparous women with normal pregnancies and, where available, their male partners (Hiby et al. 2008, 2010). Some studies included too small group of healthy couples (Ozturk et al. 2012; Vargas et al. 2009; Varla-Leftherioti et al. 2005), or both controls and cases were of mixed ethnicity (Faridi et al. 2009). Then, both the patients and controls have to be carefully selected on the basis of their clinical characteristics, age and ethnicity. We believe that our control and cases groups meet all these criteria.

In summary, our results suggest that a woman's heterozygosity in $H L A-G-716 \mathrm{~T}>\mathrm{G}$ and the LILRB1 5651 $\mathrm{G}>\mathrm{A}$ might be advantageous for success of reproduction, but the partner's heterozygosity in $9 \mathrm{~A} / 10 \mathrm{~A}$ KIR2DL4 alleles might not.

Acknowledgments This work was supported by the Polish National Science Centre Grant No. NN401 588340 in the years 2011-2014 and the programme The Leading National Research Centre (KNOW) for years 2014-2018 (to I. Nowak, Ph.D.). The authors are grateful to our volunteers for the donation of blood and their agreement to use their clinical data in this study. We would like to express our thanks also to $\mathrm{Ph} . \mathrm{D}$. Maciej Sobczynski for his help in statistical analysis.

\section{Compliance with ethical standards}

Conflict of interest The authors declare that they have no conflict of interest.

Open Access This article is distributed under the terms of the Creative Commons Attribution 4.0 International License (http:// creativecommons.org/licenses/by/4.0/), which permits unrestricted use, distribution, and reproduction in any medium, provided you give appropriate credit to the original author(s) and the source, provide a link to the Creative Commons license, and indicate if changes were made.

\section{References}

Apps R, Gardner L, Sharkey AM et al (2007) A homodimeric complex of HLA-G on normal trophoblast cells modulates antigen-presenting cells via LILRB1. Eur J Immunol 37:1924-1937

Brusilovsky M, Cordoba M, Rosental B et al (2013) Genome-wide siRNA screen reveals a new cellular partner of NK cell receptor KIR2DL4: Heparan sulfate directly modulates KIR2DL4-mediated responses. J Immunol 191:5256-5267

Brusilovsky M, Radinsky O, Yossef R et al (2014) Carbohydratemediated modulation of NK cell receptor function: structural and functional influences of heparin sulfate moieties expressed on NK cell surface. Front Oncol 4:185

Christiansen OB (2013) Reproductive immunology. Mol Immunol 55:8-15

Dahl M, Hviid TV (2012) Human leucocyte antigen class Ib molecules in pregnancy success and early pregnancy loss. Hum Reprod Update 18:92-109

Diejomaoh MF (2015) Recurrent spontaneous miscarriage is still a challenging diagnostic and therapeutic quagmire. Med Princ Pract 24(Suppl 1):38-55

Donadi EA, Castelli EC, Arnaiz-Villena A et al (2011) Implications of the polymorphism of HLA-G on its function, regulation, evolution and disease association. Cell Mol Life Sci 68:369-395

Excoffier L, Slatkin M (1995) Maximum-likelihood estimation of molecular haplotype frequencies in a diploid population. Mol Biol Evol 12:921-927

Faridi RM, Das V, Tripthi G et al (2009) Influence of activating and inhibitory killer immunoglobulin-like receptors on predisposition to recurrent miscarriages. Hum Reprod 24:1758-1764

Gómez-Lozano N, de Pablo R, Puente S et al (2003) Recognition of HLA-G by the NK cell receptor KIR2DL4 is not essential for human reproduction. Eur J Immunol 33:639-644 
Goodridge JP, Lathbury L, Steiner NK et al (2007) Three common alleles of KIR2DL4 (CD158d) encode constitutively expressed, inducible and secreted receptors in NK cells. Eur J Immunol 37:199-211

Goodridge JP, Lathbury LJ, John E et al (2009) The genotype of the NK cell receptor, KIR2DL4, influences INF gamma secretion by decidual natural killer cells. Mol Hum Reprod 15:489-497

Goris A, Dobosi R, Boonen S et al (2009) KIR2DL4 (CD158d) polymorphisms and susceptibility to multiple sclerosis. J Neuroimmunol 210:113-115

Guo Y, Lee CL, So KH et al (2013) Soluble human leukocyte antigen-G5 activates extracellular signal-regulated protein kinase signaling and stimulates trophoblast invasion. PLoS One 8:e76023

Hiby SE, Regan L, Lo W et al (2008) Association of maternal killercell immunoglobulin-like receptors and parental HLA-C genotypes with recurrent miscarriage. Hum Reprod 23:972-976

Hiby SE, Apps R, Sharkey AM et al (2010) Maternal activating KIRs protect against human reproductive failure mediated by fetal HLA-C2. J Clin Invest 120:4102-4110

Ivarsson MA, Loh L, Marquadt N et al (2013) Differentation and functional regulation of human fetal NK cells. J Clin Invest 123:3889-3901

Larsen EC, Christiansen OB, Kolte AM et al (2013) New insights into mechanisms behind miscarriage. BMC Med 11:154

Le Page ME, Goodridge JP, Zhang G et al (2013) Genetic polymorphism of KIR2DL4 (CD158d), a putative NK cell receptor for HLA-G, does not influence susceptibility to asthma. Tissue Antigens 82:276-279

Li C, Houser BL, Nicotra ML et al (2009) HLA-G homodimerinduced cytokine secretion through HLA-G receptors on human decidual macrophages and natural killer cells. Proc Natl Acad Sci USA 106:5767-5772

Makrigiannakis A, Petsas G, Toth B et al (2011) Recent advances in understanding immunology of reproductive failure. J Reprod Immunol 90:96-104

Martin AM, Kulski JK, Witt C et al (2002) Leukocyte Ig-like receptor complex (LRC) in mice and men. Trends Immunol 23:81-88

Matusita K (1955) Decision rules based on distance for problems of fit, two samples and estimation. Ann Math Statist 26:631-641

McIntire RH, Sifers T, Platt JS et al (2008) Novel HLA-G-binding leukocyte immunoglobulin-like receptor (LILR) expression patterns in human placentas and umbilical cords. Placenta 29:631-638

Medawar PB (1953) Some immunological and endocrinological problems raised by the evolution of viviparity in vertebrates. Symp Soc Exp Biol 7:320-338

Menier C, Rouas-Freiss N, Favier B et al (2010) Recent advances on the non-classical major histocompatibility complex class I HLAG molecule. Tissue Antigens 75:201-206

Meyer D, Single RM, Mack SJ et al (2006) Signatures of demographic history and natural selection in the human major histocompatibility complex loci. Genetics 173:2121-2142

Moradi S, Berry R, Pymm P et al (2015) The structure of the atypical killer cell immunoglobulin-like receptor, KIR2DL4. J Biol Chem 290:10460-10471
Niepiekło-Miniewska W, Zuk N, Dubis J et al (2014) Two new cases of KIR3DP1, KIR2DL4-negative genotypes, one of which is also lacking KIR3DL2. Arch Immunol Ther Exp 62:423-429

Nowak I, Majorczyk E, Płoski R et al (2011) Lack of KIR2DL4 gene in a fertile Caucasian woman. Tissue Antigens 78:115-119

Nowak I, Barcz E, Majorczyk E et al (2015) Genetic polymorphism of KIR2DL4 in the Polish population. Tissue Antigens $85: 450-457$

Ober C, Aldrich CL, Chervoneva I et al (2003) Variation in the HLA$\mathrm{G}$ promoter region influences miscarriage rates. Am $\mathrm{J}$ Hum Genet 72:1425-1435

Ozturk OG, Sahın G, Karacor ED et al (2012) Evaluation of KIR genes in recurrent miscarriage. J Assist Reprod Genet 29:933-938

Penn DJ, Damjanovich K, Potts WK (2002) MHC heterozygosity confers a selective advantage against multiple-strain infections. Proc Natl Acad Sci USA 99:11260-11264

Phillips JH, Hori T, Nagler A et al (1992) Ontogeny of human natural killer (NK) cells: fetal NK cells mediate cytolytic function and express cytoplasmic CD3 epsilon, delta proteins. J Exp Med 175:1055-1066

Rajagopalan S, Long EO (2012) KIR2DL4 (CD158d): an activation receptor for HLA-G. Front Immunol 3:528

Schonberg K, Fischer JC, Kogler G et al (2011) Neonatal NK-cell repertoires are functionally, but not structurally, biased toward recognition of self HLA class I. Blood 117:5152-5156

Sugiura-Ogasawara M, Ozaki Y, Suzumori N (2014) Management of recurrent miscarriage. J Obstet Gynaecol Res 40:1174-1179

Vargas RG, Bompeixe EP, França PP et al (2009) Activating killer cell immunoglobulin-like receptor genes' association with recurrent miscarriage. Am J Reprod Immunol 62:34-43

Varla-Leftherioti M, Spyropoulou-Vlachou M, Keramitsoglou T et al (2005) Lack of the appropriate natural killer cell inhibitory receptors in women with spontaneous abortion. Hum Immunol 66:65-71

Wiśniewski A, Bilińska M, Klimczak A et al (2010) Association of the HLA-G gene polymorphism with multiple sclerosis in a Polish population. Int J Immunogenet 37:307-311

Wiśniewski A, Kowal A, Wyrodek E et al (2015) Genetic polymorphisms and expression of HLA-G and its receptors, KIR2DL4 and LILRB1, in non-small cell lung cancer. Tissue Antigens $85: 466-475$

Witt CS, Martin A, Christiansen FT (2000) Detection of KIR2DL4 alleles by sequencing and SSCP reveals a common allele with a shortened cytoplasmic tail. Tissue Antigens 56:248-257

Witt CS, Whiteway JM, Warren HS et al (2002) Alleles of the KIR2DL4 receptor and their lack of association with preeclampsia. Eur J Immunol 32:18-29

Witt CS, Goodridge J, Gerbase-DeLima MG et al (2004) Maternal KIR repertoire is not associated with recurrent spontaneous abortion. Hum Reprod 19:2653-2657

Yuan HY, Chiou JJ, Tseng WH et al (2006) FASTSNP: an always upto-date and extendable service for SNP function analysis and prioritization. Nucleic Acids Res 1:34 (Web Server issue): W635-W641 